\section{B A Institute of \\ YK Business Administration \\ 六下 \\ Karachi \\ Leadership and Ideas for Tomorrow}

\section{Business Review}

Volume 16 Issue 1 January-June 2021

8-16-2021

\title{
Bonds duration and COVID-19: A study on United Kingdom conventional gilts
}

Riffat Abdul Latif Mughal

Shaheed Zulfikar Ali Bhutto Institute of Science and Technology Karachi

Follow this and additional works at: https://ir.iba.edu.pk/businessreview

Part of the Business Administration, Management, and Operations Commons, Corporate Finance Commons, and the Finance and Financial Management Commons

(c) $\underset{\mathrm{EY}}{\mathrm{i}}$

This work is licensed under a Creative Commons Attribution 4.0 International License.

\section{Recommended Citation}

Mughal, R. A. (2021). Bonds duration and COVID-19: A study on United Kingdom conventional gilts. Business Review, 16(1), 55-75. Retrieved from https://doi.org/10.54784/1990-6587.1240

This article is brought to you by iRepository for open access under the Creative Commons Attribution 4.0 License and is available at https://ir.iba.edu.pk/businessreview/vol16/iss1/1. For more information, please contact irepository@iba.edu.pk. 


\title{
Bonds duration and COVID-19: A study on United Kingdom conventional gilts
}

\author{
Riffat Abdul Latif Mughal
}

\begin{abstract}
This article studies whether the government bonds portfolio developed based on bonds duration produces abnormal returns in London Stock Exchange fixed income market during the phase of double-dip recession and COVID-19. The sample consists of UK conventional gilts traded from February 2004 till February 2021. The daily data is obtained from Thomson Reuters / Refinitiv Eikon. For this study, the data is divided into two subsamples July 2009-December 2018 and December 2019-February 2021. The findings reveal that all the bonds produced abnormal returns during the complete sample and sub-sample period when returns of UK gilts 1 year maturity are kept as a proxy for risk-free and 50-year maturity bond as a proxy for the market return. However, $R^{2}$ shows weak model of portfolios with durations 2 and 3 , which indicates that bondholders do not prefer to invest in gilts with these durations during the growth phase. The second sub-period results show weak portfolio returns with 3 , 4,8 , and 20 years of durations during the pandemic. This indicates that bondholders tend to be conservative for short-term gilts due to low and negative yields.
\end{abstract}

Keywords : Bonds' duration · UK gilts · Bond portfolio · COVID-19

\section{Introduction}

Previously, the higher acceptance of fixed-income instruments, specifically the investment in sovereign bonds, helped investors generate a continuous stream of cash flows with minimum or no risk. However, the price of bonds is exposed to interest rate risk, specifically the level risk. This risk impacts the overall holding period dollar returns on investment in fixed income securities or portfolios resulting in a parallel shift in the yield curve (Fabozzi 2001). Therefore, investors and

Riffat Abdul Latif Mughal

Shaheed Zulfikar Ali Bhutto Institute of Science and Technology Karachi-Pakistan

E-mail: riffat.mughal@szabist.edu.pk

(C)Mughal, L. A. R. 2021 
bond practitioners use different duration models as a basis for effective decisionmaking in portfolio development. In addition to that, the COVID-19 pandemic has resulted in an adverse impact on financial markets and economies. Teplova and Rodina (2021) stated, 'In a new interest rate environment, government bonds trading at low and even negative yields resulted in higher reinvestment risk largely neglected previously.' Thus, the negative yields, specifically in the United Kingdom (UK) short-term sovereign gilts, along with the double-dip recessions and COVID-19, have motivated the researcher to explore this market. Hence, for this study, UK conventional gilts (UK sovereign bonds) traded on London Stock Exchange (LSE) are selected. The main objective is to examine whether a bond portfolio based on durations helped investors earn higher returns or not? Further, the sub-sample periods helped in reviewing the duration-based bonds portfolio performance during double-dip recessions and COVID-19.

A bond price is exposed to interest rate risk. In fixed income markets, the bond duration is used to measure the price volatility and sensitivity of bonds related to the changes in interest rates. In this aspect, in his book, Fabozzi (2001) stated, 'A bond portfolio is exposed to interest rate risk as to the price of a bond or the value of a portfolio changes adversely when interest changes.' Teplova and Rodina (2021) stated that bond fund managers faced a dilemma as interest rates decreased. It is difficult for both fund managers and investors to maintain the risk and returns. However, moderate, long, and ultralong UK sovereign gilts have produced lower yields but better than short-term bonds (see figure 1). The negative interest rates have also changed the investment horizon.

The Debt Management Office (DMO) ${ }^{1}$ Chief Executive-Sir Robert Stheeman, stated, 'COVID-19 brought unprecedented challenges with serious impact on UK economy and public finance' (DMO Annual Review 2019-2020). He added that during FY2019-2020, DMO sold £115.1 billion worth of gilts. UK gilts are one of the default-free financial instruments that government uses to borrow funds directly from the investors to reduce the national deficit. The Gilts Market in the UK is bifurcated into four main categories: short $^{2}$, medium ${ }^{3}$, long $^{4}$, and ultra-long ${ }^{5}$ bonds. This distribution is based on sovereign bonds' maturities traded on the London Stock Exchange. The monthly average yields from April 1998 till February $2021^{6}$ are shown in figure 1.

The graphs showed that the average monthly yields of UK long and ultralong gilts are higher than UK short and medium gilts. However, UK short gilts have produced negative yields from July 2020 till January 2021 (see figure 1). Besides, the average monthly yields of all the gilts have been declining in the long run. Since the financial crisis of 2007-2008 and Brexit, Britain has faced a decline in growth. Further, in 2019 the country reported slow economic growth. The SkyNews (2020, November 19) said, 'The UK has dodged a recession despite

\footnotetext{
1 DMO is an agency of Her Majesty's Treasury (HM Treasury) responsible for cash and debt management in England.

2 Short gilts-all the sovereign bonds with a maturity of less than 5 years

3 Medium gilts maturities of 5 to 15 years

4 Long gilts-maturities between 15 and 30 years

5 Ultra-long gilts-maturities between 30 and 50 years

6 The data of ultra-long gilts is from June 2005 till January 2021.
} 

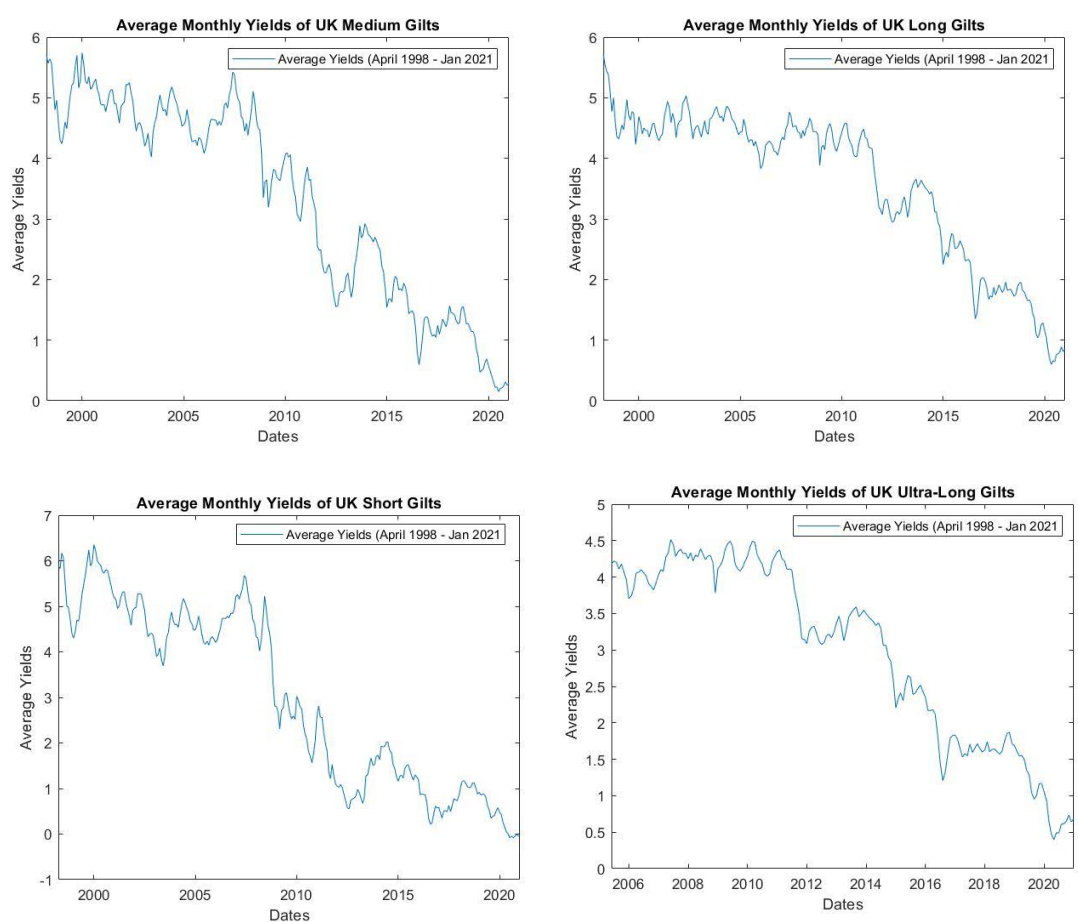

Fig. 1: Average monthly yields UK gilts-DMO

seeing the biggest year-on-year slowdown in nearly a decade.' The Guardian (2019, December 27) and BBC News (2019, October 3) informed that the British economy had reported the weakest year outside a recession mainly because of political disorders and Brexit. In the graphs below, we can see that the Bank of England reduces interest rates to recover. Also, the same can be monitored by looking at England's Monetary Policy Summary for January 2020 that the bank rate was maintained at $0.75 \%$. But COVID-19 hit the economy and as reported by NBC News (2021, February 12) the United Kingdom's economy fell by a record 10 percent in 2020 .

This critical situation can be easily examined in figure 2. The subsample from January 2019 till January 2021 of all gilts categories' monthly average yields is plotted. The short gilts have produced negative government bond returns from July 2020 till January 2021 (Figure 2c). However, the medium, long and ultra-long yields are positive and above 0 .

Teplova and Rodina (2021) stated that the long-low interest rates continue to move in descending order for decades in a surprise new reality. However, academic research has remained scarce in this area. Thus, allowing the academic researchers to explore the new dynamics of negative and lower interest rate yields and the current environment. Therefore, the study is motivated to investigate whether duration-based portfolios helped investors generate better returns or not in this lower, even negative, interest rates environment. None of the academic researchers have examined bond duration during this new era of negative yield. The complete sample was selected from February 2004 to Febru- 

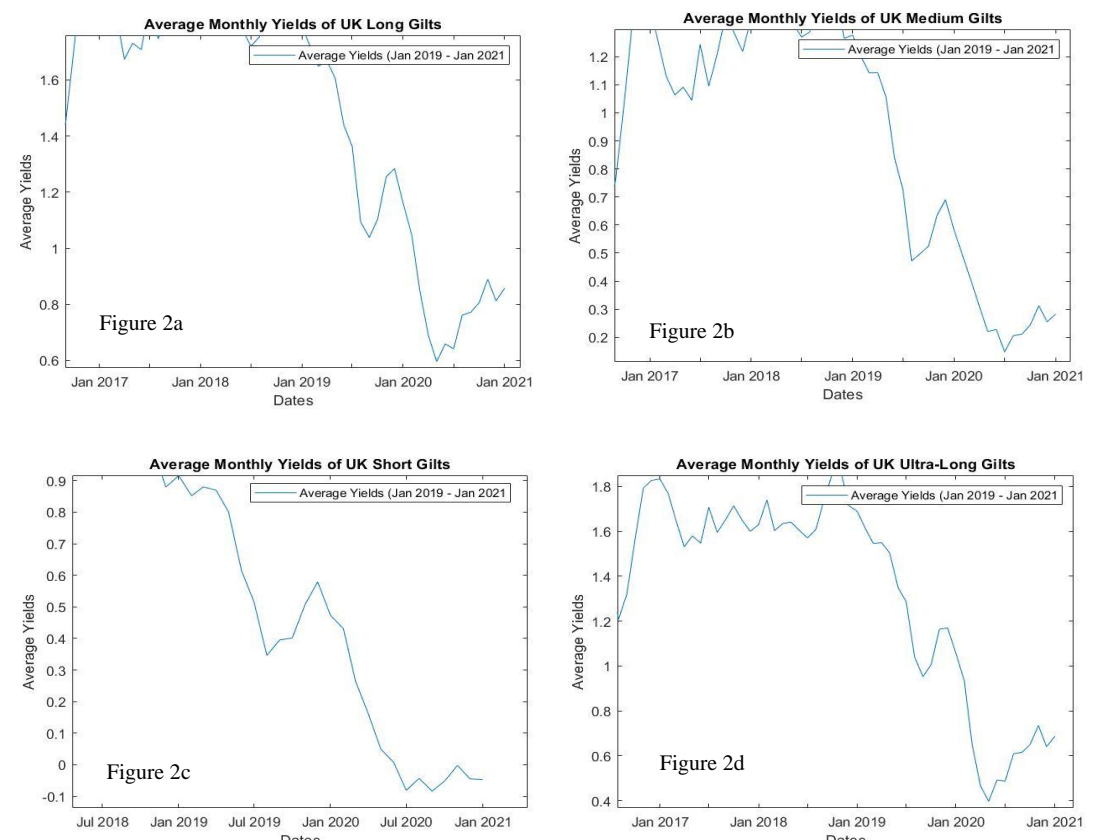

Fig. 2: UK short gilts yields during COVID-19 DMO

ary 2021 and two subsamples were from July 1, 2009, till December 31, 2018, and January 2019 till February 2021.

A few studies in this domain have been conducted. This paper covers one of the main variables: bond durations primarily used by fund managers to make investment decisions related to bonds. This paper tries to fill the research gap based on theoretical background and an empirical investigation of England's sovereign bonds in the current interest rates environment. The main motive to create bond portfolios based on bond duration is that interest rate is a single factor that impacts bond prices. Simply, bond duration is a measure of interest rate risk. This study's significance is that investors can examine the impact on returns during the lower interest rates and negative yields, upgrade their bonds portfolios to mitigate interest rate risk and change investment horizon to earn comparatively better returns.

Teplova and Rodina (2021) presented that since 2015, the volume in advanced countries, specifically negative-yielding government bonds, has exceeded $\$ 6$ trillion. The authors further mentioned that in May 2021, it surged to $\$ 12.2$ trillion after the issuance of negative yield sovereign debts in England. Teplova and Rodina (2021) and Schmelzing (2019) argued that this might persist in the future. Therefore, academic research in this domain has become compulsory.

This study's theoretical and empirical aspects are covered in upcoming sections $(2,3,4$, and 5), covering the topics; in-depth literature review, data, methodology, empirical analysis, and conclusions. These would help the readers in understanding this topic. 


\section{Literature review}

Investors have searched for investment opportunities in financial assets to generate higher returns and lower risks in finance. On the other side, the borrower of funds has searched for financing sources to minimize borrowing costs. Hence, in capital markets, bonds and stocks are significant investment sources for investors and borrowers' finance sources. In the early stages of finance, the central point of concern was the market environment and assets valuation (Dimson and Mussavian 1999). The advancement in information technology and the availability of big data analytics have assisted investors, fund managers, and researchers to conduct empirical analysis, employ investment strategies, examine bonds and stocks, and develop portfolios that can generate returns and mitigate risk.

The current paper focuses on the development of sovereign bonds portfolio based on the duration model. Schmelzing (2017) stated that in Europe, financial evolution started before the 15 th century, but none has provided analytical and performance frameworks of long-term bonds. Homer and Sylla (1996) and Schmelzing (2017) agreed that interest rate is considered the principal element of bond markets. In this context, the significant contributions of Billeter (1898), Macaulay (1938), Hicks (1939), and Kaufman (1986) are worth mentioning. In 1938, Macaulay presented the duration model as the average maturity of bonds' future stream of cash flows (Weil 1973). The author gave this formula of Macaulay Duration commonly used by finance and actuaries' practitioners;

$$
D=\sum_{i=1}^{n} t_{i} P_{t i} / \sum_{i=1}^{n} P_{t i}
$$

This equation $\sum_{i=1}^{n} t_{i} P_{t i}$ denotes the future cash flows at the time $t_{j}$, and the present value of bonds $P_{t i}$. Fisher (1966) presented an algorithm in which Macaulay duration was computed with continuous compounding interest rates. Later, Fisher and Weil (1971) introduced the expectations theory of interest rate term structures and, for the first time, examined the underlying assumptions of duration (Bierwag et al 1982). Then, Bierwag and Kaufman (1977) proposed single factor duration models (SFDM) used as a bonds' portfolio immunization strategy. After that, Bierwag and Roberts (1990) proposed an SFDM discrete duration model in which they computed the one-period bond's price through the binomial lattice, hence, calculated abnormal returns on two states $s=1,2$. They used the following equation for estimating $\beta_{t}$ as an implied measure of portfolio duration. In this equation excess return of $t$ period bond over $q$ period, the bond regressed with the excess returns of $k$ period bond over $q$ period bond.

$$
R_{t s}-R_{s q}=\beta_{t}\left(R_{s k}-R_{s q}\right)
$$

In modern studies, different aspects of bonds duration are examined, such as duration models with default risk (Fooladi et al 1997), duration and convexity gaps of macro-hedging (Fooladi and Roberts 2004), default and call risks (Xie et al 2009), sovereign risk effect on bond durations of Asian bond markets (Lee et al 2011), return risk (Becker and Ivashina, 2015) cost-effective immunization (Zaremba 2017), duration risk (Kelley 2017) and reinvestment risk premium (Teplova and Rodina 2021).

Business Review: (2021) 16(1):55-75 


\section{R. Mughal}

Further, it has been observed that most of the bonds durations studies mentioned above were done on US financial markets except for Bierwag and Roberts (1990) who examined Canadian fixed income, and Navarro et al (1997), Soto (2001), and DíAz et al (2008) who studied the Spanish bonds. No such study was found in the UK even though the country is the third-largest bond market in the world. As per the Order book for Retail Bonds (ORB) London Debt Market Overview (2015), more than 17,000 listed debt-based financial assets were listed and traded on London Stock Exchange. It means that ample opportunities are available for researchers and academicians to explore this fixed-income market. Schmelzing (2019), in Bank of England staff working paper series number 845 , studied the global real interest rates of eight centuries. The author identified that real interest rates have not been stable. Since the middle ages' significant monetary disturbances, the rates have declined between 0.6 to 1.6 basis points per annum (Schmelzing 2019). Further, the author stated that a gradual increase in real negative interest rates in advanced economies over the same horizon has been identified.

Schmelzing (2019) shed light on the current negative yield environment, 'Against their long-term context, currently depressed sovereign real rates are converging back to historical trend -a trend that makes narratives about a secular stagnation environment entirely misleading, and suggests that-irrespective of particular monetary and fiscal responses-real rates could soon enter permanently negative territory.' The authors Hamilton et al (2016) and Jordà et al (2019) argued about secular stagnation as they researched the USA, UK, and 15 advanced countries. The real global rates are not mean reverting within a specific timeframe (Hamilton et al 2016). Jordà et al (2019) found that the real safe rate (bonds and bills) has been volatile in the long run.

Akram and Li (2020) researched nominal yields of UK gilts. In this study, the authors examined whether the short-term interest rate drives the long-term rate in the UK or not? The authors stated that the macroeconomic issues and policy debates related explicitly to government bond yields in monetary transmission mechanism, government and private sector debts elucidate the concern (Akram and Li 2020). Further, the global crisis, including the financial and debt crisis and the most recent pandemic COVID-19, influenced central banks to take action and respond quickly to the challenges faced, such as 'financial market turbulence and economic dislocations' (Akram and Li 2020). The results showed a significant influence on the yields, and the results stayed the same even after including control variables.

Ellison and Scott (2020) studied UK national debt by taking a dataset from 1694 till 2018 and UK gilts' issuance from the government perspective. The authors studied the fluctuations in the value of debt to find out the one-period holding returns. In actuality, the investors' returns are the cost of debt that government has to pay for borrowing funds to overcome their budget deficit. The findings showed a substantial cost advantage if the government issues short-term UK gilts considering operational risks in making semiannually coupon payments and redemptions (Ellison and Scott 2020). The authors also highlighted that after the financial crisis 2007-2008, the long-term rates decreased in the UK, and 'triggered unfavorable revaluation effects and extra costs in the form of high one 
period holding returns on long gilts' (Ellison and Scott 2020).

Schwendner et al (2015) examined European bonds before Brexit by using the sample 2004-2015. The authors studied the sovereign risks of government bonds in different subsamples. The results showed a positive correlation between the time structure and bond yields from 2004 till 2009. Later on, Schwendner et al (2019) conducted research and reported the three events related to European bond markets that gained public interest after 2015. These political events were the Brexit referendum (2016), the French presidential elections (2017), and Italian budget negotiations (2018). According to the authors, a spillover pattern of negative sentiment was observed. However, in the UK, the negative sentiments were reversed quickly, but the pound's devaluation remained (Schwendner et al 2019. Hence, the above researches of Schwendner et al $(2015,2019)$ have encouraged the author to take the time frame from February 2004 till February 2021 and the subsample from July 1, 2009, till December 31, 2018.

The in-depth literature review showed that none of the research studies have examined the UK gilts fixed income market during COVID-19 and recent double-dip recessions; this research will therefore make a valuable contribution to literature in that area. Thus, the second sub-sample selected is from January 2019 till February 2021. The empirical model and research methodology are discussed next.

\section{Empirical model, data and methodology}

Based on the literature review, Bierwag and Roberts (1990) approach is used in the current study. The discrete empirical model of partial equilibrium helped in the development of duration-based bond portfolios. According to the authors, 'The single factor duration models are derived from the underlying stochastic process of interest rates term structures' (Bierwag and Roberts 1990). In the model mentioned earlier, beta is considered a proxy of stochastic process and measures duration. At first, discrete returns of period bonds are computed using equation 3 .

$$
R_{t}=\frac{P(1, t)}{P(0, t)}
$$

Here, $P(0, t)$ denotes the current market price of a default-free bond that promises to pay £1 return at the end of the holding period (Bierwag and Roberts 1990). At the end of the first period, the bond would be $P(1, t)$. Then, the following model is used for computing $\beta$, which is the measure of the stochastic process and portfolio duration.

$$
R_{i \tau}-R_{q \tau}=\beta_{t \tau}\left(R_{k \tau}-R_{q \tau}\right)+\mu_{t \tau}
$$

In equation $4, R_{t \tau}$ represents per Great Britain Pound (GBP) return during $t$ period $(t=1,2,3 \ldots$ and $\tau=1,2,3$..). For portfolio construction, three bonds with different maturities are selected. Based on durations, UK gilt's excess return of $t$ period bond during the holding period $\tau$ is chosen in a portfolio. Then, 
two reference securities with $k$ and $q$ periods are selected, ensuring $k \neq q$. Excess returns of $t$ period sovereign bond with $q$ period reference security and $k$ period bond are computed. In simple terms, the excess return of $t$ and $q$ period sovereign bonds is proportional to the excess returns of $t$ and $k$ period with $k$ fixed income default-free securities at $\tau$ holding period or investment horizon. Therefore, $\beta_{t}$ is the measure of volatility or risk factor. The three UK gilts with different maturities are selected based on duration.

The daily database for UK gilts was gathered from Thomson Reuters / Refinitiv Eikon from February 2004 till February 2021. The dataset provides approximately 4,318 total observations of each variable. The missing values (mostly comprised of weekends and public holidays) were deleted, resulting in 4318 observations for each analysis variable. In LSE, the gilts were traded on five working days; therefore, this data is considered for analysis. The midmarket prices, ask and bid prices, basis points, yields to maturity, and durations time series data were extracted from Eikon. The midmarket prices are equal to the average of ask and bid prices over the period under consideration for this study. Twenty categories of conventional gilts are traded on LSE. The list of variables and sovereign bonds along with RIC codes is provided in table A1 (see appendix).

Further, short maturities bonds, including one month, three months, and six months along with medium maturities gilts nine years and twelve years, are eliminated due to data unavailability. In this research, thirteen portfolios are constructed. The returns of gilts are considered as risk-free and denoted by $R_{q}$, the 50-year gilts' returns are represented by $R_{k}$, and gilts with 2 through 10 years, $15,20,25,30$, and 40 years are denoted by $R_{t}$. By using equation 4 , abnormal returns and market returns were computed and regressed. For analysis, the study has used Bierwag and Roberts (1990) single factor duration model. This model is based on Sharpe's (1964) capital asset pricing model. Many prominent authors have used this model in their researches on UK bonds for instance; Barron et al (1997); Abad et al (2010); He et al (2018); Abakah et al (2021). Moreover, Bierwag and Roberts (1990) were the pioneers, and their significant contribution to literature has motivated the use of their model and methodology for bullet portfolio development construction and analysis.

The same approach is used to examine whether portfolios constructed by taking subsample from the recessionary phase followed by COVID-19 or not. For this, the subsample from January 2019 till February 2021 is selected for analysis. The second subsample used is from July 1, 2009, till December 31, 2018, as the database is available for UK gilts with different durations categories (excluding subprime crisis 2008 dataset).

\section{Empirical findings and discussion}

4.1 Basic summary statistics

The descriptive statistics of variables are shown in table-1. 


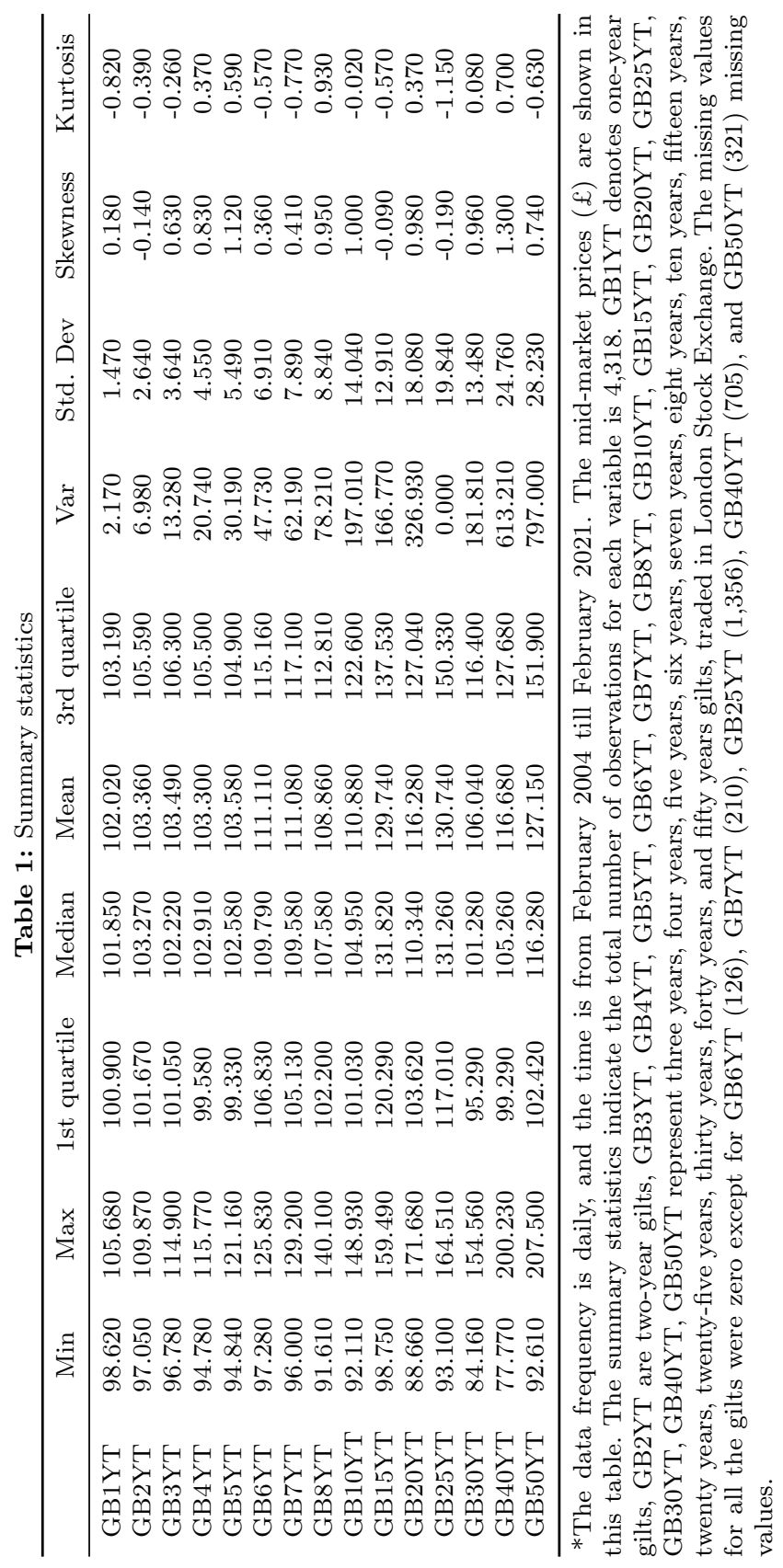

Business Review: (2021) 16(1):55-75 
In table-1, the minimum (min) mid-market price of GB1YT (1-year maturity UK gilt) is $£ 98.62,1$ st quartile is $£ 100.90$, the median is $£ 101.85$, 3rd quartile is $£ 103.19$, maximum $(\max )$ price is $£ 105.68$, mean is $£ 102.02$ and standard deviation (SD) is 1.47 . The quartile statistics divide the data into four equal parts, and the median represents the middlemost value. GB2YT is a short-term bond with a maturity of 2 years; the data shows that the midmarket price is in the range of $£ 97.05$ and $£ 109.87$, the value of $£ 101.67$ is the 1st quartile, and $£ 105.59$ is 3 rd quartile, with a mean of $£ 103.36$, the median of 103.27 and SD of 2.64. The short-term gilts with 3,4 , and 5 years of maturities show that the midmarket prices range between $£ 96.78-£ 114.90, £ 94.78$ $£ 115.77$, and $£ 94.84$ - £121.16. The 1st quartiles mid-market prices of 3,4 , and 5 years gilts are $£ 101.05, £ 99.58, £ 99.33$, median values are $£ 102.22, £ 102.91$, $£ 102.58$, and the 3 rd quartiles are $£ 106.30, £ 105.50$, and £104.90. The mean values of these gilts are $£ 103.49, £ 103.30$, and $£ 103.58$, and standard deviations are $3.64,4.55$, and 5.49. The medium-term bonds $6,7,8$, and 10 years maturities gilts mid prices were between $£ 97.28$ - £125.83, £96.0 - £129.2, £91.61 - $£ 140.10$, and $£ 92.11$ - $£ 148.93$. The quartiles statistics of medium gilts are; 1st quartiles $£ 106.83, £ 105.13, £ 102.20$, and $£ 101.03,2$ nd quartiles or medians are $1109.79, £ 109.58, £ 107.58$, and $£ 104.95$, and 3rd quartiles are £115.16, $£ 117.10, £ 112.81$, and $£ 122.60$. The mean measure of central tendency shows $£ 111.11, £ 111.08$, £108.86, and £110.88, and standard deviations of $6.91,7.89$, 8.84, and 14.04 .

The long maturity gilts such as $15,20,25$, and 30 years mid prices fall in the ranges of $£ 98.75-£ 159.49, £ 98.75-£ 159.49, £ 88.66$ - £171.68, and £93.10 - £164.51. The descriptive statistics show 1st quartiles of $£ 120.29, £ 103.62$, $£ 117.01$, and £95.29, mean of £129.74, £116.28, £130.74, and £106.04, the median of $£ 131.82$, £110.34, £131.26, and £101.28, 3rd quartiles of $£ 137.53$, $£ 127.04, £ 150.33$, and $£ 116.40$, and standard deviations of $12.91,18.08,19.84$, and 13.48. The gilts with ultra-long maturities are 40 and 50 years, and their prices are between $£ 77.77$ - 2200.23 and $£ 92.61$ - 207.50 . The summary statistics of these government bonds represent $£ 99.29$ and $£ 102.42$, the median of $£ 105.26$ and $£ 116.28$, mean of $£ 116.68$ and $£ 127.15$, 3rd quartiles of $£ 127.68$ and $£ 151.90$, and standard deviations of 24.76 and 28.23 . The mid-market prices show that the longer the bond maturities, the greater the gap between the minimum and maximum prices, offering abnormal capital gain. The standard deviation, which is the square root of variances, shows that the higher the maturity higher the dispersion. The skewness indicates that the values of all the gilts fall in between -0.2 and +1.30 . The kurtosis values are in the range of -1.15 and +0.7 , showing the normality of the data. It is also used as a measure of financial risk. In addition, the variances of short-term bonds are less like GB1YT is 2.17; however, as the duration and maturities increase, the variance also increases for GB50YT bond it is 797, indicating higher risk. The quartile statistics show the equal distribution of data into four quartiles or interquartile range, which measures variability around the median (Liberto, 2021). The low level of kurtosis of short maturity bonds shows lower risk as returns are relatively low compared to the moderate risk associated with the long-term government bonds that offer higher returns than short-maturity bonds. 
The descriptive statistics of durations are presented in table A2 (see appendix). After descriptive statistics, discrete returns of all the UK gilts are computed and then the correlation among Great Britain Pound gilts returns is examined.

\subsection{Correlation statistics and stationery}

As Bierwag and Roberts (1990) mentioned, the returns of one class's durations could be correlated with other durations bonds' returns. Thus, for UK gilts, the correlation test is executed. The results are shown in table-2. The main findings show that all the returns with different durations are correlated. The one-year gilts returns are positively related to $2,3,6,8,25$, and 50 years gilts returns except for other gilts. The two-year gilts have a positive relationship with 1,3 , $4,7,15,19,25$, and 50 years bonds. However, the following gilts' returns have a negative correlation such as three years durations based returns are negatively related with 5, 6, and 8 years gilts, four years returns with 1, 6, and 10, five years returns with 1, 2, 3, 6 and 10 years gilts. The correlation results of returns per pound show that all the correlation values are less than 76 , which means no multicollinearity and serial correlation exists. 


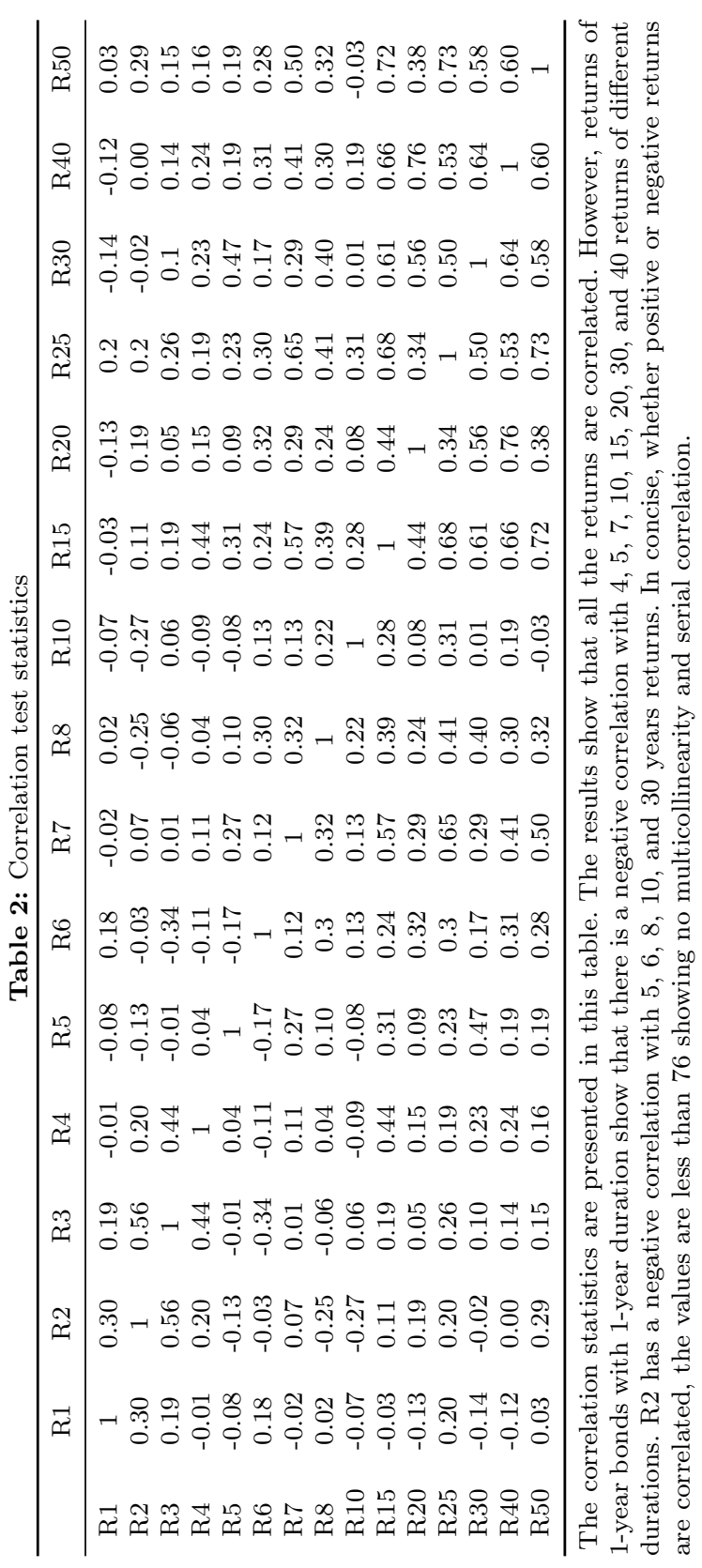


After this test, the data series' stationarity is examined by plotting each return for different durations. The figures (A-1, A-2, A-3) are shown in the appendix. Specific extreme values and incomplete samples are due to recessions of 2008, 2019, and COVID-19. Hence, it is one reason why data has been bifurcated into three subsamples. The model estimation and analysis are presented in the next section.

\subsection{Model fit, estimation, and analysis}

The model estimation is done on three sets of data time series. First, the complete data series from February 2004 till February 2021 has been selected. The estimated results of equation (4) for the entire dataset are provided in table-3.

The results show that the portfolio of 2 years duration model has $\beta_{1}=$

Table 3: Model 1 Estimation results (complete sample February 2004 till February 2021)

\begin{tabular}{lccccc}
\hline Duration & \multicolumn{2}{c}{ Beta estimates } & \multicolumn{2}{c}{ Alpha estimates } & $R^{2}$ \\
\hline & Coefficients & t-value & Coefficients & t-value & \\
\hline 2 & 0.060 & 16.170 & -0.000 & -0.120 & 0.061 \\
3 & 0.051 & 10.560 & 0.000 & 0.030 & 0.027 \\
4 & 0.072 & 13.620 & 0.000 & 0.150 & 0.044 \\
5 & 0.129 & 12.550 & 0.000 & 0.090 & 0.038 \\
6 & 0.137 & 15.310 & -0.000 & -0.300 & 0.057 \\
7 & 0.182 & 22.200 & -0.000 & -0.760 & 0.115 \\
8 & 0.170 & 17.970 & -0.000 & -0.240 & 0.075 \\
10 & 0.054 & 2.760 & 0.000 & 0.720 & 0.002 \\
15 & 0.337 & 51.330 & -0.000 & -0.160 & 0.398 \\
20 & 0.442 & 31.900 & -0.000 & -0.210 & 0.203 \\
25 & 0.439 & 61.060 & 0.000 & 0.970 & 0.558 \\
30 & 0.593 & 53.660 & -0.000 & -0.350 & 0.419 \\
40 & 0.689 & 51.700 & -0.000 & -0.390 & 0.426 \\
\hline
\end{tabular}

Abnormal Returns for different durations categories $R_{t}(2,3,4,5,6$, $7,8,10,15,20,25,30$, and $40\left(R_{t}-R_{q}\right)$ regressed on Abnormal Returns $\left(R_{k}-R_{q}\right)$. $R_{q}=$ Returns of 1 year and $R_{k}=$ Returns of 50 years reference securities at period $t$. The results show that all the portfolios Beta coefficients are significant at a $1 \%$ significance level. These results include 4318 observations from February 2004-February 2021.

0.06040 , t-statistics $=16.17$, and $R^{2}=0.0614$, representing excess returns of reference securities $\left(R_{50}-R_{1}\right)$ does have a significant impact on excess returns of $\left(R_{2}-R_{1}\right)$. The $\beta_{1 t}$ estimates of all the portfolios in table 3 are significant at a 99 percent confidence level. However, none of the intercept values are significant. The $R^{2}$ of durations $2,3,4,5,6,8$, and 10 are less than $10 \%$. The best model fits are of portfolios with durations $15,25,30$, and 40 , indicating that the returns of risk-free securities with 1-year durations in the portfolio and the returns of reference security with 50 years of duration is considered as a proxy for market returns than investment in long-term duration UK gilts provides higher returns. The $R^{2}$ of the portfolio with ten years of duration shows the weakest 
estimates.

Then, subsample portfolios from January 2019 till February 2021 are selected because England reported slow growth and recession. In addition to that, COVID-19 had the worst effect on world's economies, including England. The results are shown in table- 4 .

The results show all beta estimates are significant at a $1 \%$ significance level.

Table 4: Model 2 Estimation results (sub sample January 2019 till February 2021)

\begin{tabular}{|c|c|c|c|c|c|}
\hline \multirow[t]{2}{*}{ Duration } & \multicolumn{2}{|c|}{ beta estimates } & \multicolumn{2}{|c|}{ alpha estimates } & \multirow[t]{2}{*}{$R^{2}$} \\
\hline & Coefficients & t-value & Coefficients & t-value & \\
\hline 2 & 0.074 & 12.320 & 0.000 & 0.070 & 0.219 \\
\hline 3 & 0.012 & 2.820 & -0.000 & -0.240 & 0.015 \\
\hline 4 & 0.018 & 3.540 & 0.000 & 0.400 & 0.023 \\
\hline 5 & 0.063 & 12.610 & 0.000 & 0.300 & 0.227 \\
\hline 6 & 0.079 & 17.530 & -0.000 & -0.650 & 0.363 \\
\hline 7 & 0.083 & 16.520 & -0.000 & -0.220 & 0.336 \\
\hline 8 & 0.040 & 5.490 & 0.000 & 0.480 & 0.053 \\
\hline 10 & -0.407 & -13.630 & 0.001 & 0.790 & 0.256 \\
\hline 15 & 0.156 & 16.300 & 0.002 & 0.860 & 0.330 \\
\hline 20 & 0.274 & 5.890 & 0.000 & 0.330 & 0.060 \\
\hline 25 & 0.254 & 15.590 & 0.000 & 0.080 & 0.310 \\
\hline 30 & 0.377 & 14.190 & 0.000 & 0.020 & 0.272 \\
\hline 40 & 0.493 & 17.900 & -0.000 & -0.220 & 0.291 \\
\hline
\end{tabular}

* All beta coefficients are significant at $99 \%$ confidence interval. The results are based on 542 observations. All the beta estimates are significant.

All the alpha estimates are insignificant and agree with Bierwag and Roberts (1990). The $R^{2}$ shows the suitable model fit in per pound returns of portfolios created based on durations $2,5,6,7,10,15,25,30$, and 40. However, portfolios $3,4,8$, and 20 are weak. It means that during the period of Covid-19, investors have considered an investment in UK gilts as it provides a continuous stream of cashflows.

The third model is constructed for the subsample period July 2009-December 2018 (see table-5). The phase in which England's economy performed better as compared to the recession 2019 and onwards.

Beta coefficients are significant at a $99 \%$ confidence interval. The $R^{2}$ of the weak model of portfolios with durations 2 and 3 years is less than $5 \%$, indicating that investors do not prefer to invest in bonds with these durations during the growth phase. Portfolios 4, 5, 6, 8, and 10 are moderately good, and portfolios with durations of $7,15,20,25,30$, and 40 have very good $R^{2}$. The results represent that medium, long, and ultra-long UK gilts are preferred over short gilts. The results are similar to Teplova and Rodina (2021). The researchers used the cointegration technique; the results suggest that investors tended to be more conservative in the UK sovereign bonds market and forecast medium maturity bonds than the short-term, mainly because of higher returns in the mediumterm gilts as compared to short-term. Also, short-term gilts have a lower level and interest rate risk profile. At the time of crisis, the investors also showed in- 
Table 5: Model 3 Estimation Results (sub Sample July 2009 till December 2018)

\begin{tabular}{lccccc}
\hline Duration & \multicolumn{2}{c}{ Beta estimates } & \multicolumn{2}{c}{ Alpha estimates } & $R^{2}$ \\
\hline & Coefficients & t-value & Coefficients & t-value & \\
\hline 2 & 0.052 & 10.570 & -0.000 & -0.220 & 0.044 \\
3 & 0.079 & 11.240 & -0.000 & -0.350 & 0.050 \\
4 & 0.113 & 12.150 & -0.000 & -0.380 & 0.058 \\
5 & 0.181 & 11.700 & -0.000 & -0.310 & 0.054 \\
6 & 0.178 & 15.500 & -0.000 & -0.120 & 0.091 \\
7 & 0.270 & 31.540 & -0.000 & -1.290 & 0.312 \\
8 & 0.269 & 15.970 & -0.000 & -0.180 & 0.096 \\
10 & 0.435 & 21.800 & -0.000 & -0.280 & 0.165 \\
15 & 0.461 & 78.820 & -0.000 & -0.210 & 0.721 \\
20 & 0.546 & 42.490 & -0.000 & -0.860 & 0.428 \\
25 & 0.632 & 103.110 & 0.000 & 0.630 & 0.815 \\
30 & 0.752 & 46.450 & -0.000 & -1.030 & 0.472 \\
40 & 0.854 & 48.030 & -0.000 & -0.610 & 0.489 \\
\hline
\end{tabular}

* All beta coefficients are significant at $1 \%$ significance level. In this sub sample, number of observations are 2411. Excess Returns for different durations categories $R_{t}(2,3,4,5,6,7,8,10,15,20,25,30$, and $40\left(R_{t}-R_{q}\right)$ regressed on Excess Returns $\left(R_{k}-R_{q}=\right.$ Returns of 1 year and $R_{k}=$ Returns of 50 years reference securities at time period $t$.

terest in medium, long and ultra-long gilts. From a policy perspective, the HM treasury and DMO have reduced the yields to zero and even negative. Investors can be forced to give government medium-term or long-term loans to finance their deficit. Further, after Brexit, the government has issued 40 and 50 years maturity bonds to finance their current economic growth.

\section{Conclusion}

The main findings drawn from the estimation and analysis sections are that all the single factor duration models' beta estimates are significant in the complete sample. For 20, 25, 30, and 40 years duration, portfolio returns betas show higher impact as long-run investors get higher returns than short-run UK gilts. These findings are also supported by $R^{2}$. The second observation is that during the times of recessions, in England, 15, 20, 25, 30, and 40 years durations portfolios have reported higher beta coefficient values with better $R^{2}$. Thus, supporting the fact that investors earned higher returns by investing in long and ultra-long UK gilts. The third observation is made by looking at the sub-sample period from July 2009 till December 2018 that during the better economic conditions, bonds portfolios with $7,15,20,25,30$, and 40 years durations have performed well. Thus, we can say that during the growth phase, medium (10 and 15 years), long (20 and 25 years), ultra-long (30 and 40 years) portfolios have provided better returns in the UK fixed income market.

The use of single-factor duration models can assist investors in making strategic decisions for fixed-income portfolios. A single factor duration model is used; however, two-factor and three-factor models can also be studied in developed and developing economies. The key findings suggest that the Bank of 
England influences gilts' nominal yields and sets the key policy rate. This supports the results of Akram and Li (2020) that monetary policy actions affect long-term rates. The results would contribute to fixed income literature and contribute to the ongoing debates of negative yields and the determinants and interest rate risk associated with government bond yields. Further, investors, fund managers, and investment bankers can modify their bonds portfolio to mitigate interest rate and level risks to protect from losses and generate returns. From a policy perspective, as Ellison and Scott (2020) stated, the UK policy of issuing long-term maturity bonds would substantially increase the debt's market value. Further, all the gilts' yields declined, specifically short-term yields during COVID-19 and recent double-dip recessions in the UK economy. It would trigger unfavorable revaluation effects on the UK government as they might have to bear extra costs by offering higher one-period holding returns (Ellison and Scott 2020) on medium, long and ultra-long gilts.

\section{References}

Abad P, Chuliá H, Gómez-Puig M (2010) Emu and european government bond market integration. Journal of Banking \& Finance 34(12):2851-2860

Abakah EJA, Addo Jr E, Gil-Alana LA, Tiwari AK (2021) Re-examination of international bond market dependence: Evidence from a pair copula approach. International Review of Financial Analysis 74:101,678

Akram T, Li H (2020) The empirics of uk gilts' yields. Levy Economics Institute, Working Papers Series (969)

Barron MJ, Clare AD, Thomas SH (1997) The effect of bond rating changes and new ratings on uk stock returns. Journal of Business Finance \& Accounting 24(3):497-509

Bierwag GO, Kaufman GG (1977) Coping with the risk of interest-rate fluctuations: a note. The Journal of Business 50(3):364-370

Bierwag GO, Roberts GS (1990) Single-factor duration models: Canadian tests. Journal of Financial Research 13(1):23-38

Bierwag GO, Kaufman GG, Toevs AL (1982) Single factor duration models in a discrete general equilibrium framework. The Journal of Finance 37(2):325-338

DíAz A, de la O GOnzález M, Navarro E (2008) Bond portfolio immunization, immunization risk and idiosyncratic risk. Revista de Economía Financiera (16)

Dimson E, Mussavian M (1999) Three centuries of asset pricing. Journal of Banking \& Finance $23(12): 1745-1769$

Ellison M, Scott A (2020) Managing the uk national debt 1694-2018. American Economic Journal: Macroeconomics 12(3):227-57

Fabozzi FJ (2001) Bond portfolio management, vol 73. John Wiley \& Sons

Fisher L (1966) An algorithm for finding exact rates of return. The Journal of Business 39(1):111-118

Fooladi I, Roberts GS (2004) Macrohedging for financial institutions: beyond duration. Journal of Applied Finance 14(1)

Fooladi IJ, Roberts GS, Skinner F (1997) Duration for bonds with default risk. Journal of Banking \& Finance 21(1):1-16

Hamilton JD, Harris ES, Hatzius J, West KD (2016) The equilibrium real funds rate: Past, present, and future. IMF Economic Review 64(4):660-707

He Z, O'Connor F, Thijssen J (2018) Is gold a sometime safe haven or an always hedge for equity investors? a markov-switching capm approach for us and uk stock indices. International Review of Financial Analysis 60:30-37

Homer S, Sylla RE (1996) A history of interest rates. Rutgers University Press

Jordà Ò, Knoll K, Kuvshinov D, Schularick M, Taylor AM (2019) The rate of return on everything, 1870-2015. The Quarterly Journal of Economics 134(3):1225-1298 
Kelley AG (2017) Duration risk: Do you know your numbers? Review of Business \& Finance Studies 8(1):57-66

Lee HW, Xie YA, Yau J (2011) The impact of sovereign risk on bond duration: Evidence from asian sovereign bond markets. International Review of Economics \& Finance 20(3):441451

Navarro E, Nave JM, et al (1997) A two-factor duration model for interest rate risk management. Investigaciones económicas 21(1):55-74

Schmelzing P (2017) Eight centuries of the risk-free rate: bond market reversals from the venetians to the var shock

Schmelzing P (2019) Eight centuries of global real interest rates, rg, and the supraseculardecline, 1311-2018. RG, and the SuprasecularDecline pp 1311-2018

Schwendner P, Schuele M, Ott T, Hillebrand M (2015) European government bond dynamics and stability policies: taming contagion risks

Schwendner P, Schüle M, Hillebrand M (2019) Sentiment analysis of european bonds 20162018. Frontiers in Artificial Intelligence 2:20

Soto GM (2001) Immunization derived from a polynomial duration vector in the spanish bond market. Journal of banking \& finance 25(6):1037-1057

Teplova TV, Rodina VA (2021) The reinvestment risk premium in the valuation of british and russian government bonds. Research in International Business and Finance 55:101,319

Weil RL (1973) Macaulay's duration: An appreciation. The Journal of Business 46(4):589-592

Xie YA, Liu S, Wu C, Anderson B (2009) The effects of default and call risk on bond duration. Journal of Banking \& Finance 33(9):1700-1708

Zaremba L (2017) Does macaulay duration provide the most cost-effective immunization method: A theoretical approach. Foundations of Management 9(1):99-110

\section{Appendix}

Table A1: Thomson Reuters RIC Codes

\begin{tabular}{|c|c|c|}
\hline \multicolumn{2}{|c|}{ RIC Codes for UK Gilts } & \multirow{2}{*}{$\begin{array}{l}\text { Variables } \\
\text { ASK.Close }\end{array}$} \\
\hline $\mathrm{GB} 1 \mathrm{MT}=\mathrm{RR}$ & $\mathrm{GB} 8 \mathrm{YT}=\mathrm{RR}$ & \\
\hline $\mathrm{GB} 3 \mathrm{MT}=\mathrm{RR}$ & $\mathrm{GB} 9 \mathrm{YT}=\mathrm{RR}$ & Bid.Close \\
\hline $\mathrm{GB} 6 \mathrm{MT}=\mathrm{RR}$ & $\mathrm{GB} 10 \mathrm{YT}=\mathrm{RR}$ & BPV.Value \\
\hline $\mathrm{GB} 1 \mathrm{YT}=\mathrm{RR}$ & $\mathrm{GB} 12 \mathrm{YT}=\mathrm{RR}$ & DURATION.Value \\
\hline $\mathrm{GB} 2 \mathrm{YT}=\mathrm{RR}$ & $\mathrm{GB} 15 \mathrm{YT}=\mathrm{RR}$ & YLDTOMAT.Value \\
\hline $\mathrm{GB} 3 \mathrm{YT}=\mathrm{RR}$ & $\mathrm{GB} 20 \mathrm{YT}=\mathrm{RR}$ & MID_PRICE.Value \\
\hline $\mathrm{GB} 4 \mathrm{YT}=\mathrm{RR}$ & $\mathrm{GB} 25 \mathrm{YT}=\mathrm{RR}$ & \\
\hline $\mathrm{GB} 5 \mathrm{YT}=\mathrm{RR}$ & $\mathrm{GB} 30 \mathrm{YT}=\mathrm{RR}$ & \\
\hline $\mathrm{GB} 6 \mathrm{YT}=\mathrm{RR}$ & $\mathrm{GB} 40 \mathrm{YT}=\mathrm{RR}$ & \\
\hline $\mathrm{GB} 7 \mathrm{YT}=\mathrm{RR}$ & $\mathrm{GB} 50 \mathrm{YT}=\mathrm{RR}$ & \\
\hline
\end{tabular}

Business Review: (2021) 16(1):55-75 


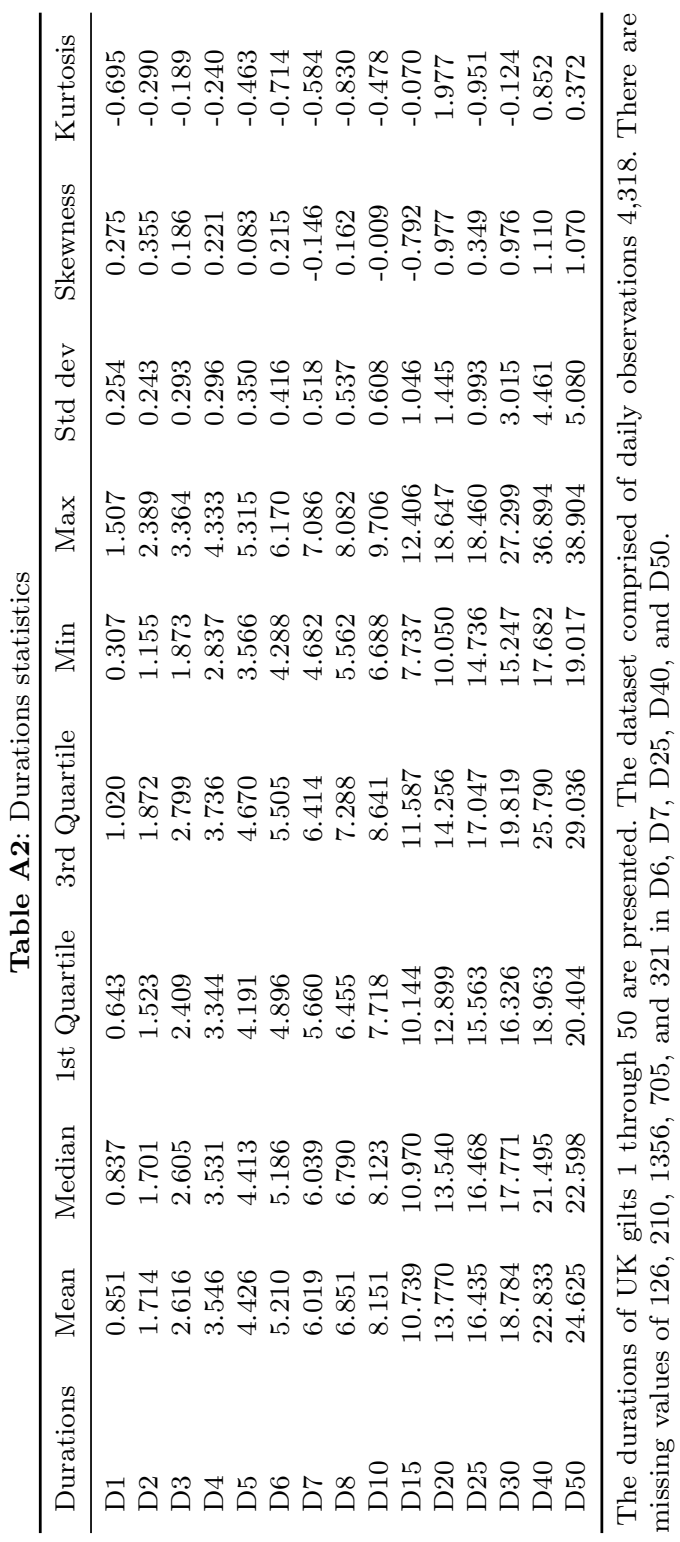



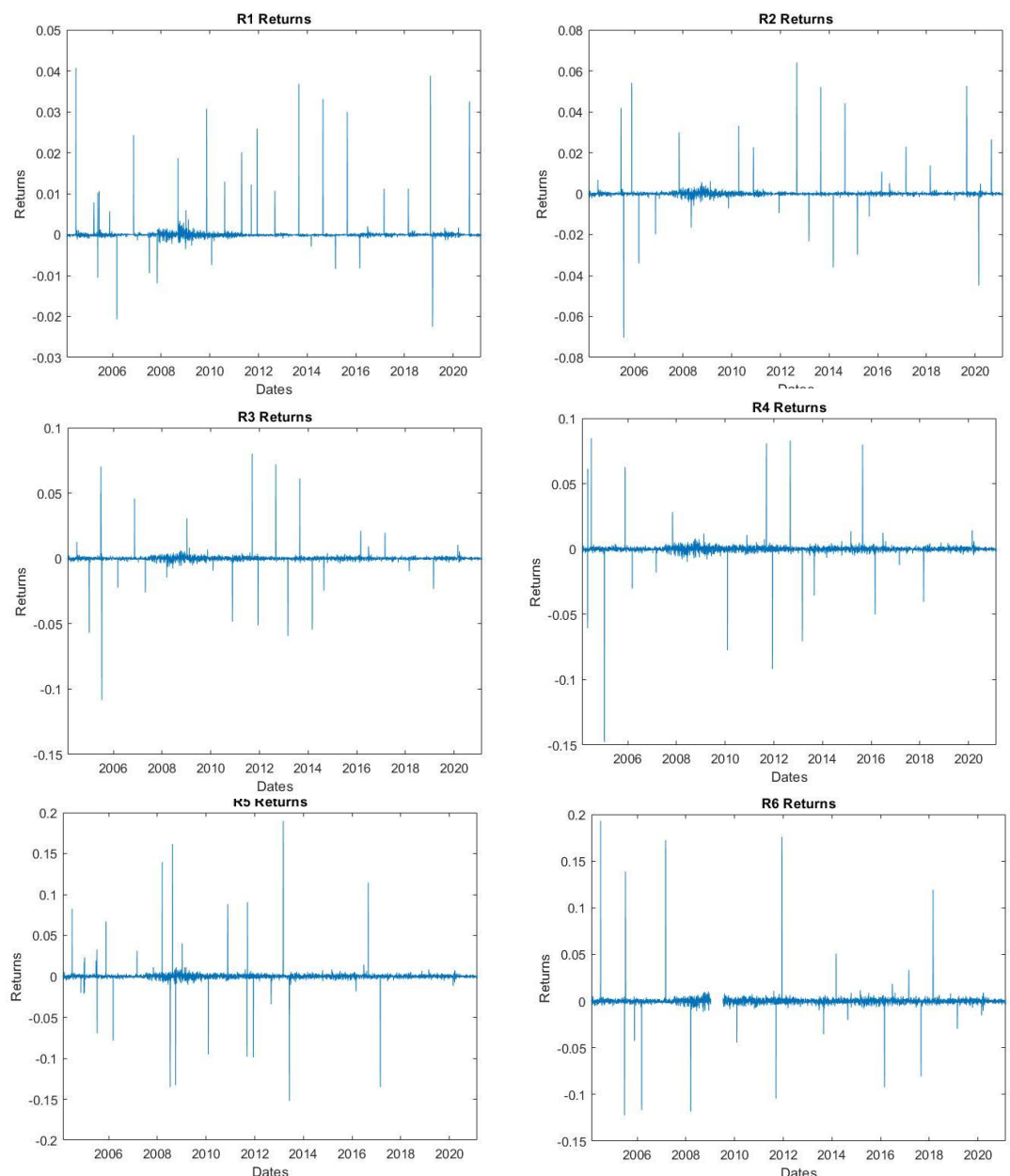

Figure A-1: Stationary Series of R1, R2 R3, R4, R5, and R6 

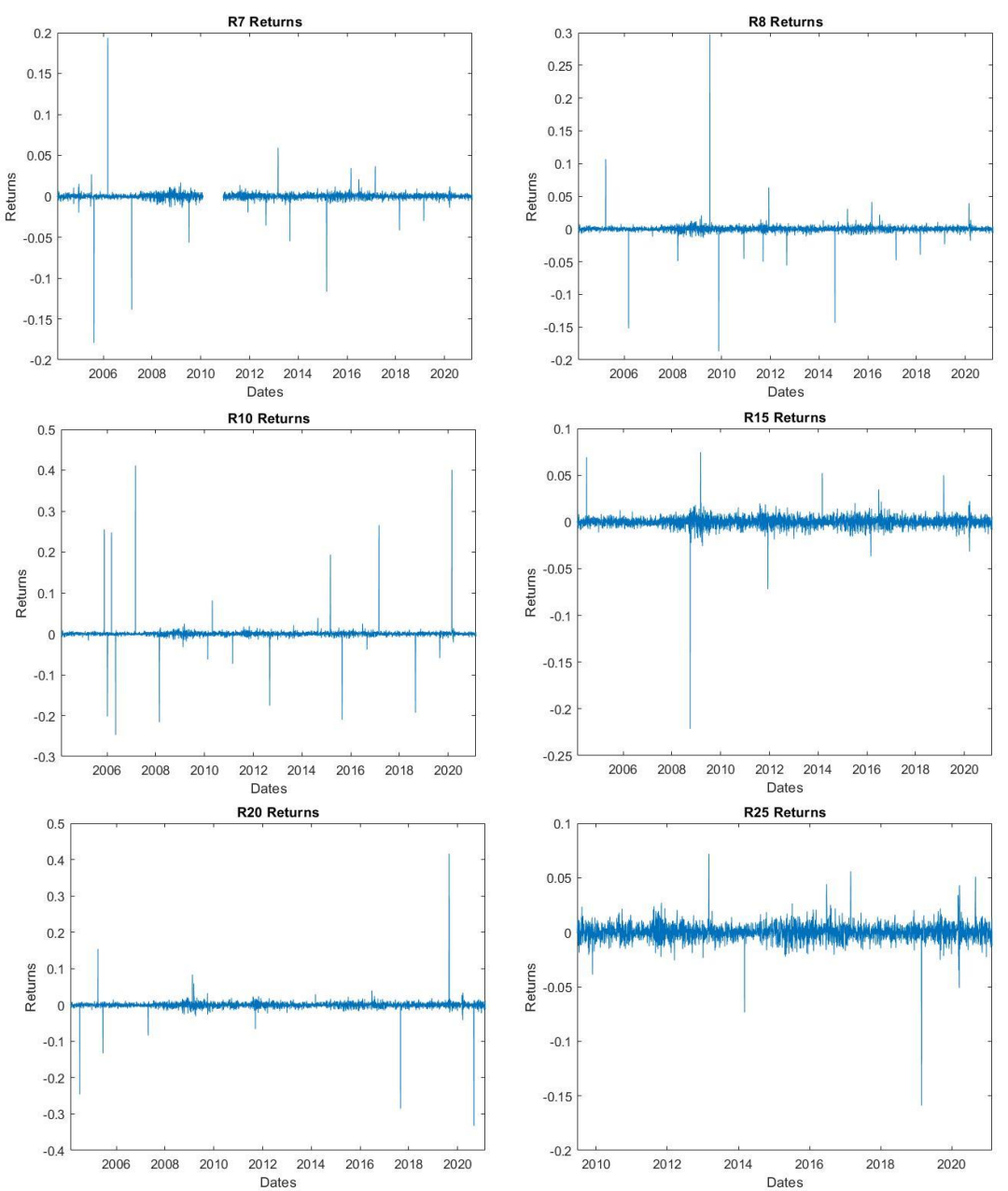

Figure A-2: Stationary Series R7, R8, R10, R15, R20, and R25 

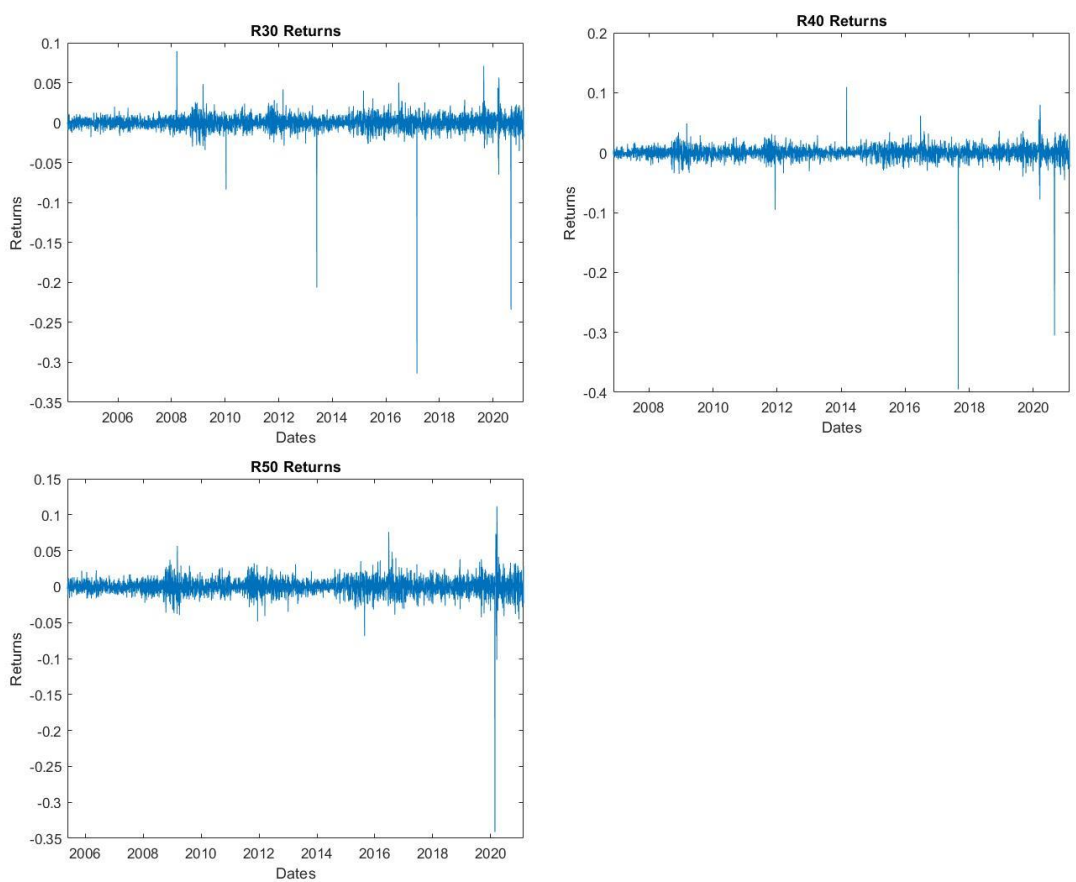

Figure A-3: Stationary Series R30, R40, and R50 